\title{
Crónica comunitaria: la actualidad institucional y económica de España en el marco de la Unión Europea
}

\author{
Beatriz Iñarritu Ibarreche \\ Profesora de la Universidad Comercial de Deusto
}

\begin{abstract}
Sumario: Introducción.-I. El estado de la integración. 1. La firma del Tratado de Estabilidad, Coordinación y Gobernanza (TECG). 2. Tratado Constitutivo del Mecanismo Europeo de Estabilidad (MEDE). I.3. Serbia: Estado candidato a la adhesión. - II. La actualidad institucional de la Unión Europea. 1. Consejos Europeos y Cumbres del euro del primer semestre de 2012: medidas contra la crisis del euro y tratado internacional sobre el «pacto fiscal». 2. Renovación de Van Rompuy como Presidente del Consejo Europeo y de la Cumbre del euro. 3. Iniciativa legislativa de los ciudadanos europeos. - III. Cuestiones generales de la actualidad económica. 1. España: rescate del sector bancario. 2. Recia: reestructuración de la deuda privada. 3. BCE: nueva inyección ilimitada de liquidez a la Banca Europea. 4. Mercados financieros: propuestas sobre una tasa a las transacciones financieras. 5. Google: denuncia de la Comisión por abuso de posición dominante en el mercado y recurso prejudicial ante el Tribunal de Justicia. 6. Tarifas máximas en la conexión a internet a través del teléfono móvil. 7. Reforma del Tratado Schengen.
\end{abstract}

\section{Introducción}

La Unión Europea está atravesando un momento crítico como consecuencia de la grave crisis financiera a que se enfrenta, y que está llegando a amenazar con abrir una gran brecha en la integración europea.

El clima de desconfianza y de reproches mutuos entre los Estados miembros, causado por los anteriores excesos de unos y las actuales exigencias de otros, junto con los pasos demasiado cortos y tardíos que se están dando en la solución de la crisis, podrían estar minando el futuro de Europa, no sólo a nivel político sino por la frustración que están produciendo en la ciudadanía.

Es difícil para los ciudadanos entender el «inagotable» apoyo al sector financiero, mientras los recortes y los ajustes en las Economías más vulnerables continúan y es difícil comprender también que los avances en forma 
de Tratados sobre el «Pacto Fiscal» y el Mecanismo financiero permanente no consiguen la confianza de los mercados.

Nunca antes una «mayor Europa» ha sido tan necesaria. Una Europa más fuerte que de pasos de solidaridad, integración y cohesión, de la mano de líderes que sepan transmitir esperanza y, sobre todo, sentido común, en esta difícil coyuntura.

The EU is facing a critical time as a result of the deep financial crisis, which is indeed threatening to open a great gap in the European integration.

The climate of distrust and mutual reproaches among member States, caused by the previous excesses of some of them and the current requirements of others, together with the steps, too short and late, taken to solve the crisis, might be undermining the future of Europe, and not only at a political stage but because of the frustration they are transmitting to the European citizens.

It is so difficult to understand the 'endless' support to the financial sector, while cuts and adjustments go on in those more vulnerable Economies, as it is also difficult to understand that those progresses achieved with the Treaties about the 'Fiscal Pact' and the permanent financial Mechanism are not gaining the confidence of the markets.

Never before a 'greater Europe' was so necessary. A stronger Europe that should take steps of solidarity, integration and cohesion, guided by those leaders that should know how to transmit hope and, above all, common sense, in this complex situation.

\section{El estado de la integración}

\section{Firma del Tratado de Estabilidad, Coordinación y Gobernanza (TECG)}

El 2 de marzo se celebró la firma solemne del Tratado de Estabilidad, Coordinación y Gobernanza en la Unión Económica y Monetaria, TECG, conocido también como el «Pacto Fiscal».

Tras el acuerdo alcanzado en la Cumbre del Euro del 9 de diciembre de 2011 sobre una «arquitectura reforzada para la Unión Económica y Monetaria», Veinticinco Jefes de Estado y de Gobierno (salvo los del Reino Unido y República Checa) rubricaron en Bruselas un Tratado que consagra la austeridad económica, puesto que obliga a los países firmantes a un estricto control de sus cuentas públicas. 
El Tratado contempla tres grandes capítulos:

1. Pacto Presupuestario

El Tratado incluye una nueva regla que establece que los presupuestos nacionales estén en equilibrio o en superávit. Se considerará que se respeta esta disposición si se cumple el objetivo por país a medio plazo tal como se define en el Pacto de Estabilidad y Crecimiento, y con el límite del «déficit estructural» del 0,5\% del PIB.

Si se observaran desviaciones importantes en dicho objetivo o en la trayectoria de ajuste al mismo, se activará un mecanismo automático de adopción de medidas correctoras.

Esta norma debe incorporarse al Derecho nacional en el plazo de un año tras la entrada en vigor del Tratado a través de disposiciones que «tengan fuerza vinculante y sean de carácter permanente, preferentemente de rango constitucional, o cuyo respeto o cumplimiento estén de otro modo plenamente garantizados a lo largo de los procedimientos presupuestarios nacionales».

El Tribunal de Justicia de la UE podrá verificar la transposición de esta regla de equilibrio presupuestario y, en su caso, estará facultado para imponer multas de hasta el 0,1\% del PIB del país incumplidor.

El Tratado también establece que los Estados firmantes deberán informar sobre sus planes de emisión de Deuda pública al Consejo de la UE y a la Comisión Europea.

2. Coordinación de las Políticas Económicas y Convergencia Los Estados firmantes deberán garantizar que todas las grandes reformas de política económica que proyecten llevar a cabo se debatirán previamente y, en su caso, se coordinarán entre sí.

3. Gobernanza de la Zona del Euro

Se celebrarán reuniones informales de la «Cumbre del Euro» en las que participarán los Jefes de Estado o de Gobierno de los países pertenecientes a la Unión Monetaria, cuando sea necesario y, como mínimo, dos veces al año. Los líderes de los países firmantes del Tratado excluidos del Euro participarán en los debates de las cumbres.

Con el fin de evitar un retraso significativo en su aplicación, el Tratado prevé su entrada en vigor tras la ratificación en Doce de los Diecisiete Estados miembros de la Eurozona, siendo la fecha límite el 1 de enero de 2013. El objetivo que se plantea el propio Tratado es su incorporación en la legislación de la UE al cabo de cinco años desde su entrada en vigor.

Portugal fue el primer país en ratificar el Tratado el 13 de Abril a través de una votación parlamentaria, y con el apoyo aplastante de los diputados 
de la coalición de centro-derecha del gobierno y de una gran mayoría de los diputados socialistas, principal partido de la oposición.

Por su parte, Irlanda celebró el 31 de mayo un referéndum para proceder a su ratificación (es el único país que, obligado por su Constitución, ha previsto celebrar una votación popular). Con una participación de apenas el $50,6 \%$, los irlandeses dieron su apoyo al nuevo Tratado, con un margen más amplio de lo anticipado, el 60,3\% de votos favorables. El primer ministro irlandés, Enda Kenny, acogió con alivio y satisfacción el resultado, y señaló que aunque el apoyo popular al Tratado «no resuelve todos nuestros problemas económicos, es una piedra fundacional para asegurar que la Economía se sostendrá en tierra firme».

\section{Tratado Constitutivo del Mecanismo Europeo de Estabilidad (MEDE)}

El 2 de febrero, los embajadores de los países de la zona euro firmaron en Bruselas el Tratado constitutivo del Mecanismo Europeo de Estabilidad, MEDE.

Esta firma necesitó la modificación del artículo 136 del Tratado de Funcionamiento de la Unión Europea, añadiendo el apartado siguiente: «Los Estados miembros cuya moneda es el euro podrán establecer un mecanismo de estabilidad que se activará cuando sea indispensable para salvaguardar la estabilidad de la zona del euro en su conjunto. La concesión de toda ayuda financiera necesaria con arreglo al mecanismo se supeditará a condiciones estrictas».

En julio de 2011, los Jefes de Estado y de Gobierno de los Diecisietes habían acordado incrementar la flexibilidad de MEDE con vistas a aumentar la eficacia de la asistencia financiera y a prevenir el riesgo de contagio financiero. Tras los últimos acuerdos, y pendiente de su ratificación por los Estados participantes, es previsible que entre en vigor en julio de 2012.

El MEDE será, por tanto, una institución financiera internacional con sede en Luxemburgo que apoyará a los Estados de la eurozona cuando sea indispensable para salvaguardar la estabilidad financiera.

Las decisiones para conceder la asistencia financiera se adoptarán de mutuo acuerdo (unanimidad de los participantes en la votación). No obstante, en aquellas situaciones en las que el hecho de no adoptar estas decisiones pudiera poner en peligro la sostenibilidad económica o financiera de la zona del euro, las decisiones podrán ser adoptadas por una mayoría cualificada del $85 \%$ de los votos emitidos. 
El artículo 12 del Tratado establece que «si fuera indispensable para salvaguardar la estabilidad financiera de la zona del euro en su conjunto y de sus Estados miembros, el MEDE podrá proporcionar apoyo a la estabilidad a un miembro del MEDE sujeto a estricta condicionalidad, adaptada al instrumento de asistencia financiera elegido. Dicha condicionalidad podrá adoptar diversas formas, desde un programa de ajuste macroeconómico hasta una obligación de cumplimiento continuo de las condiciones de elegibilidad preestablecidas».

El procedimiento descrito en el artículo 13 establece que, sobre la base de la solicitud del miembro del MEDE y de la evaluación realizada por la Comisión en coordinación con el Banco Central Europeo, «el Consejo de Gobernadores del Mecanismo podrá decidir conceder, en principio, apoyo a la estabilidad al miembro del MEDE en cuestión mediante un instrumento de asistencia financiera».

Asimismo, el Consejo de Gobernadores encomendará a la Comisión Europea negociar con el miembro del MEDE en cuestión - en coordinación con el BCE y, cuando ello sea posible, conjuntamente con el FMI - un «Memorándum de Entendimiento» en el que se defina con precisión la condicionalidad asociada al instrumento de asistencia financiera. El contenido del «Memorándum» reflejará la gravedad de las deficiencias que habrá que abordar y el instrumento de asistencia financiera elegido.

El Tratado prevé que el MEDE pueda conceder a sus Estados miembros préstamos, poner a su disposición instrumentos financieros con carácter preventivo, adquirir bonos públicos en los mercados primario y secundario y conceder préstamos a los países para financiar la recapitalización de sus instituciones financieras.

El capital autorizado ascenderá a 700.000 millones de euros, dividido en siete millones de acciones, cada una con un valor nominal de 100.000 euros.

El valor nominal total inicial de las acciones desembolsadas se elevará a 80.000 millones de euros, de tal manera que cada Estado miembro del MEDE deberá realizar el pago en cinco tramos anuales del $20 \%$ cada uno del importe total. El primer tramo será desembolsado por cada miembro del MEDE en el plazo de 15 días tras la fecha de entrada en vigor del Tratado. Los cuatro tramos restantes serán exigibles en las fechas correspondientes al primer, segundo, tercer y cuarto aniversario del pago del primer tramo, respectivamente.

Los Estados suscribirán el capital conforme a la siguiente «clave de contribución»: 


\section{Suscripciones del capital autorizado}

\begin{tabular}{lrr}
\hline \multicolumn{1}{c}{ Miembro del MEDE } & Número de acciones & $\begin{array}{r}\text { Suscripción del capital } \\
\text { (eur) }\end{array}$ \\
\hline Reino de Bélgica & 243.397 & 24.339 .700 .000 \\
República Federal de Alemania & 1.900 .248 & 190.024 .800 .000 \\
República de Estonia & 13.020 & 1.302 .000 .000 \\
Irlanda & 111.454 & 11.145 .400 .000 \\
República Helénica & 197.169 & 19.716 .900 .000 \\
Reino de España & 833.259 & 83.325 .900 .000 \\
República Francesa & 1.427 .013 & 142.701 .300 .000 \\
República Italiana & 1.253 .959 & 125.395 .900 .000 \\
República de Chipre & 13.734 & 1.373 .400 .000 \\
Gran Ducado de Luxemburgo & 17.528 & 1.752 .800 .000 \\
Malta & 5.117 & 511.700 .000 \\
Reino de los Países Bajos & 400.190 & 40.019 .000 .000 \\
República de Austria & 194.838 & 19.483 .800 .000 \\
República Portuguesa & 175.644 & 17.564 .400 .000 \\
República de Eslovenia & 29.932 & 2.993 .200 .000 \\
República Eslovaca & 57.680 & 5.768 .000 .000 \\
República de Finlandia & 125.818 & 12.581 .800 .000 \\
\hline \multicolumn{1}{c}{ Total } & 7.000 .000 & 700.000 .000 .000 \\
\hline
\end{tabular}

Fuente: Tratado Constitutivo del Mecanismo Europeo de Estabilidad.

\section{Serbia: Estado Candidato a la Adhesión}

El Consejo Europeo celebrado en marzo decidió conceder a Serbia el estatuto de país candidato a ser Estado miembro de la Unión, refrendando así las conclusiones del Consejo de Ministros de Asuntos Exteriores de la Unión celebrado el 28 de febrero.

Los Veintisiete recompensaban de esta manera los avances del país balcánico en su acercamiento a las exigencias de la UE, incluyendo la detención de los últimos prófugos reclamados por el Tribunal Penal Internacional y un acuerdo con Kosovo que le permitirá acudir a foros internacionales.

Sin embargo, el triunfo del nacionalista Tomislav Nikolic en las elecciones presidenciales celebradas el 20 de mayo parece haber enturbiado el camino del país hacia su integración en la UE.

A pesar de que, nada más conocer su victoria Nikolic señaló que «Serbia no se desviará de la vía europea», su anterior alianza con un partido abiertamente hostil con la UE había servido a sus adversarios para poner en duda la veracidad de su compromiso a favor de la Adhesión del país a la Unión. 
De hecho, a comienzos de junio, la UE emitió un comunicado en el que desautorizaba al nuevo presidente serbio por haber negado la limpieza étnica ejecutada por las tropas serbiobosnias en la localidad de Srebrenica en julio de 1995. Bruselas rechazó su «intento de reescribir la historia» y recordó que el Tribunal Penal de La Haya califica este hecho como «genocidio».

Con su nuevo estatuto, Serbia se une a los actuales países candidatos: Islandia y Turquía, que ya negocian su Adhesión, y Macedonia y Montenegro, que se encuentran a la espera de iniciar sus respectivas negociaciones.

\section{La actualidad institucional de la Unión Europea}

\section{Consejos Europeos y Cumbres del Euro del primer semestre de 2012: Medidas contra la Crisis Del Euro y Tratado Internacional sobre el «Pacto Fiscal»}

Hasta mediados de junio, se han celebrado tres reuniones de los Jefes de Estado y de Gobierno de los Veintisiete, previas a la reunión ordinaria prevista para el 28 y 29 de junio.

El 30 de enero se celebró un Consejo Europeo con los Veintisiete y, también se convocó una reunión específica los Diecisiete líderes de la Eurozona.

Según las interpretaciones de diferentes medios y analistas, en esta primera cumbre del año, los Veintisiete mostraron un medido viraje en su discurso sobre las medidas a adoptar para combatir la crisis. A las puertas de una nueva recesión económica, los líderes europeos acordaron compaginar las reiteradas medidas de austeridad y de reducción de los Déficits públicos con recetas de expansión y crecimiento, enfocadas a frenar el desempleo. Decidieron, en este sentido, destinar unas partidas de los fondos estructurales pendientes de asignación (fondos de «competitividad y crecimiento») a la creación de empleo. En total son 82.314 millones de euros, cuyo objetivo será facilitar el acceso de los jóvenes al mercado laboral y apoyar a las PYMEs.

Asimismo, los líderes europeos llegaron al consenso sobre el contenido del Tratado internacional que establece el «Pacto Fiscal», con la adhesión final de todos los Estados miembros, salvo las del Reino Unido y República Checa.

También el 1 y 2 de marzo se celebraron sendas reuniones, del Consejo Europeo y de la Cumbre del Euro.

De nuevo, los analistas interpretaron que la UE mostraba un giro en sus soluciones de la crisis económica al plantear la necesidad de una actuación «dirigida a fomentar el crecimiento, la competitividad y el empleo», como vertiente complementaria de las medidas «orientadas a garantizar la estabilidad financiera y la consolidación presupuestaria». 
Aunque bajo los enunciados generales, se apreciaban pocas ideas concretas, los líderes comunitarios pedían hacer más atractiva la contratación para los empresarios, mejorar las políticas para el empleo juvenil y el fomento de la innovación y del crecimiento.

Jose Manuel Barroso, presidente de la Comisión Europea, mencionó como objetivos concretos la creación de planes de empleo juvenil y la financiación de proyectos de pequeñas empresas con fondos del Banco Europeo de Inversiones.

Por su parte, el presidente del Banco Central Europeo, Mario Draghi, previno a los socios comunitarios de que la acción extraordinaria que había adoptado la autoridad monetaria en los últimos meses - inyectar más de un billón de euros en la banca europea a un interés muy bajo - probablemente no volvería a repetirse y que tendrían que ser los Estados quienes tomasen a partir de entonces las riendas para aliviar las tensiones financieras.

Por último, el 23 de mayo se celebró una reunión informal del Consejo, para debatir sobre las decisiones previstas en la agenda económica del siguiente Consejo Europeo de los días 28 y 29 de junio.

Según fuentes comunitarias, la presentación del nuevo presidente francés, Francois Hollande, fue uno de los motivos que llevaron al Consejo Europeo a convocar la cumbre informal. Además, otra razón del encuentro fue, según las mismas fuentes, el interés de Irlanda de que la Unión mostrara públicamente su intención de fomentar el crecimiento y el empleo, antes del referéndum del 31 de mayo, en el que el pueblo irlandés debía pronunciarse sobre el «Pacto Fiscal». Y también debió ser un motivo para convocar la reunión la voluntad de rebajar las suspicacias entre los socios europeos y mostrar que las decisiones se toman entre los Veintisiete, y que Berlín y París no hablan por toda Europa.

La cumbre sirvió, en todo caso, para escenificar los nuevos tiempos, e iniciar un nuevo debate sobre los eurobonos, que se convirtieron, de hecho, en un tema de controversia entre Francia y Alemania.

En su «bautizo» en las cumbres europeas, el nuevo presidente francés, François Hollande, aseguró que «Alemania piensa que los eurobonos son un punto de llegada, y Francia cree que son un punto de partida». Y dejó claro que su propuesta se abriría paso, a pesar de que junto con Alemania hay varios países radicalmente en contra: «Los eurobonos no son para mutualizar la deuda del pasado, sino que pueden servir para lograr financiación en mejores condiciones: «Alemania está pagando un interés del $0 \%$ y España financia su deuda al $6 \%$, y con los eurobonos se podría financiar a coste más bajo», añadió el presidente francés.

A más corto plazo, los socios concretaron la puesta en marcha de nuevas medidas para estimular el crecimiento, y en particular una nueva línea de financiación a través del Banco Europeo de Inversiones (BEI) para au- 
mentar las posibilidades de que los jóvenes griegos, portugueses, españoles e italianos encuentren un empleo, además de apoyar proyectos de infraestructuras, energía e I+D. El presidente de la Comisión Europea, José Manuel Durão Barroso, explicó que el BEI ha recibido un mandato que consiste en una ampliación de capital de unos 10.000 millones de euros, con los que podría movilizar hasta 150.000 millones junto con el sector privado.

Los Veintisiete mostraron también su acuerdo en la defensa de la permanencia de Grecia en el euro y del cumplimiento de las obligaciones a las que se ha comprometido. Los presidentes de la Comisión y del Consejo Europeo, Barroso y Van Rompuy, anunciaron el envío de fondos estructurales para impulsar el crecimiento e informaron de los 150.000 millones que había recibido ya entonces Atenas de la Unión y del Fondo Monetario Internacional.

\section{Renovación de Van Rompuy como Presidente del Consejo Europeo $y$ de la Cumbre del Euro}

El Consejo Europeo celebrado en marzo oficializó la reelección de Herman Van Rompuy como su Presidente para el período comprendido entre el 1 de junio de 2012 y el 30 de noviembre de 2014.

Por su parte, en la Declaración de los Jefes de Estado o de Gobierno de la zona del euro del 2 de marzo también se contemplaba su nombramiento como Presidente de las Cumbres del Euro. Se cumplía así el acuerdo alcanzado en el Consejo Europeo de 23 de octubre de 2011 en el que se establecía que «el Presidente de la Cumbre del Euro será designado por los Jefes de Estado o de Gobierno de la zona del euro a la vez que el Consejo Europeo elija a su presidente y para el mismo período».

De esta forma, el ex primer ministro belga cumplirá un ciclo de cinco años al frente de las cumbres europeas, desde la entrada en vigor del Tratado de Lisboa. La reelección era ya un hecho desde que, unos meses atrás, tanto Francia como Alemania le dieran su apoyo y porque ni se había planteado un candidato alternativo.

Desde que accedió al cargo en diciembre de 2009, Van Rompuy ha ofrecido un perfil discreto y conciliador, aunque en ocasiones se le ha reprochado que no se desmarcara con propuestas propias, distintas de las líneas marcadas por el eje franco-alemán.

\section{Iniciativa Legislativa de los Ciudadanos Europeos}

El pasado 1 de abril entró en vigor el Reglamento de la Iniciativa Ciudadana Europea que permite a los ciudadanos europeos plantear iniciativas invitando a la Comisión Europea a legislar sobre determinados temas. 
Las iniciativas deberán contar con el respaldo de, al menos, un millón de firmas de europeos residentes en un mínimo de siete Estados miembros (una cuarta parte de los Veintisiete Estados). De esta manera, los ciudadanos podrán instar al ejecutivo comunitario a que proponga un texto legislativo relativo a alguno de los temas en los que esté facultado para desarrollar dichas propuestas legislativas, temas como agricultura, medio ambiente, transporte o salud pública.

Los impulsores de las iniciativas deberán crear un «comité de ciudadanos» que deberá estar integrado, al menos, por siete ciudadanos de la UE residentes en, al menos, siete Estados miembros distintos. El comité deberá inscribir su iniciativa en el registro de la página web que la Comisión ha habilitado al efecto, de tal forma que, una vez confirmada la inscripción, se abrirá un plazo de un año para la recogida de firmas. Podrán firmar el apoyo a la iniciativa todos los ciudadanos de la UE con edad mínima para votar, debiendo en todo caso rellenar un formulario específico que servirá para certificar las firmas por parte de las autoridades competentes en los Estados miembros.

Una vez reunidas y verificadas las firmas, la Comisión dispondrá de tres meses para examinar el texto y pronunciarse al respecto. Los promotores se reunirán con los representantes de la Comisión para explicarles los detalles e, incluso, podrían presentar la iniciativa al Parlamento Europeo. Tras el análisis, la Comisión aprobará un documento oficial en el que explicará si considerará o no la iniciativa popular, y las razones que le habrán llevado a tal decisión. Si decidiera seguir adelante, también deberá explicar las medidas que se propondría llevar a cabo en el futuro y la Comunicación sería adoptada formalmente por el colegio de comisarios y publicada en todas las lenguas oficiales de la UE. De esta forma, si Bruselas decidiera legislar en respuesta a una iniciativa ciudadana, se pondrá en marcha el procedimiento legislativo habitual: la propuesta de la Comisión se remitirá al Parlamento Europeo y al Consejo, o únicamente al Consejo, y estas instituciones tendrán la última palabra para decidir si la propuesta de la Comisión se convierte en norma comunitaria.

\section{Cuestiones generales de la actualidad económica}

\section{España: rescate del sector bancario}

El Consejo de Ministros de Finanzas de la zona euro, el Eurogrupo, decidió el 9 de junio atender la solicitud del gobierno español para apoyar la recapitalización de su sistema financiero.

La asistencia, destinada a los bancos españoles, consistirá en una línea de crédito que podría llegar a 100.000 millones de euros, cifra que equivale 
al 10\% del PIB español. El crédito se prestará a un interés medio del 3\%, muy por debajo de las condiciones de mercado (el Tesoro español paga actualmente un interés superior al 6\% por la Deuda a diez años).

El préstamo, que se concederá a través del Fondo de Reestructuración de Ordenación Bancaria, FROB, estará dirigido a reflotar los maltrechos bancos españoles, que se han visto arrastrados por la enorme burbuja inmobiliaria. Para hacer efectivo el crédito se exigirá a las entidades beneficiaras que activen los «planes de reestructuración» correspondientes, lo que significa que, eventualmente, deberán deshacerse de parte de sus activos, participaciones empresariales e inmuebles, deberán recortar los gastos de personal y/o poner en marcha nuevas fusiones o, incluso, liquidaciones.

La Comisión Europea señaló, tras la aprobación del rescate, que la supervisión de estas medidas correrá a cargo de un cuarteto de organismos: la propia Comisión, el Banco Central Europeo, el Fondo Monetario Internacional y la Autoridad Bancaria Europea.

Aunque no se trata de una intervención integral, al estilo de los programas puestos en marcha en Grecia, Irlanda o Portugal, y se entiende como un «rescate suave» dirigido exclusivamente al sector financiero y no al país en su conjunto, el rescate del sistema financiero español ha provocado una fuerte reacción en la sociedad española. La intervención ha sido interpretada como un fracaso colectivo, y ha provocado un intenso debate sobre el alcance y los perjuicios que finalmente tendrá la ayuda europea en el bienestar de la ciudadanía española.

El FROB, institución de capital público, será el intermediario que proporcione hasta 100.000 millones de euros a las entidades financieras que los necesiten. El garante final de las operaciones será, por tanto, el Estado español, por lo que los eventuales impagos repercutirán negativamente en las cuentas públicas.

Aunque explícitamente el Eurogrupo, el Fondo Monetario Internacional y la Comisión Europea no han establecido «condicionalidades macroeconómicas» con nuevos y más estrictos ajustes, resulta más que improbable que tales exigencias no se plantearan. De hecho, en el comunicado emitido por los ministros de Finanzas de la zona euro se señala que Europa supervisará «de cerca» que Madrid continúe por el camino de la consolidación fiscal y de las reformas estructurales y del mercado de trabajo.

Muchos analistas recuerdan, en este sentido, los informes de la Comisión que, a finales de Mayo, han recomendado a España la subida del IVA, el adelanto para hacer efectiva la edad de jubilación a los 67 años, la reforma de las prestaciones por desempleo o la eliminación de la deducción fiscal por la compra de vivienda.

En todo caso, existen dudas relevantes sobre la concreción del programa, que deberían resolverse en el Consejo Europeo del 28 y 29 de ju- 
nio. Está pendiente, por ejemplo, la decisión sobre el fondo que se utilizará, el temporal o el permanente. Podrían emplearse los dos, el Fondo Europeo de Estabilidad Financiera (FEEF) temporal o el Mecanismo Europeo de Estabilidad (MEDE) permanente, que entrará en vigor en julio de 2012. Los Estados preferirían el segundo, puesto que esta herramienta prevé que los países sean acreedores preferentes, y que los inversores privados se vean relegados en el cobro de sus deudas.

El Fondo Monetario Internacional, FMI, no será un prestamista de los bancos españoles, como sí lo es en los rescates de Grecia, Irlanda y Portugal; pero sí intervendrá con su apoyo en la supervisión de las operaciones con informes periódicos.

Por otra parte, el 13 de junio, la Oficina de Estadísticas de la UE, EUROSTAT, señaló en un comunicado que «el crédito aceptado por el gobierno español aumentará directamente la Deuda pública y el gasto de los intereses del préstamo también tendrá un impacto directo en el Déficit».

Además, señalaba que determinadas recapitalizaciones bancarias también podrían aumentar el Déficit público. Según el organismo europeo, aun es demasiado pronto para conocer el impacto preciso de las intervenciones sobre el Déficit de las cuentas españolas, pero como regla general, el dinero que el Gobierno dedique a los bancos se considerará gasto público y, por lo tanto, engrosará el Déficit cuando la intención del ejecutivo sea cubrir las pérdidas de una entidad bancaria. En cambio, señalaba la agencia estadística, cuando el Estado actúe como lo haría un inversor privado, buscando una rentabilidad, estaría haciendo una transacción financiera, sin consecuencias para el Déficit.

Esta cuestión significará que, por ejemplo, el dinero público destinado a Bankia, que tratará de cubrir la falta de solvencia de la entidad por las pérdidas en que ha incurrido, computará a efectos del Déficit. Otras recapitalizaciones que pueden necesitar Novagalicia y CatalunyaCaixa también podrían incrementarlo. En todo caso, Eurostat matiza que analizará las recapitalizaciones caso a caso junto a las autoridades españolas.

Estas consideraciones harán más difícil la consecución del objetivo de Déficit del gobierno español, y podrían añadir nuevos argumentos a los socios europeos para forzar nuevos recortes y ajustes en las cuentas públicas españolas.

\section{Grecia: reestructuración de la deuda privada}

Grecia dio el 8 de marzo un paso decisivo en el cierre de la reestructuración de su Deuda soberana que evitaba finalmente una quiebra descontrolada del país. 
La operación era el resultado de un acuerdo alcanzado entre el Gobierno griego y la organización que engloba a los 450 mayores grupos financieros del mundo, el Instituto de Finanzas Internacionales (IIF, por sus siglas en inglés), para condonar la mitad de la deuda griega en manos de inversores privados.

Inversores que controlaban un $85 \%$ de la Deuda griega registrada bajo las leyes helenas, 152.000 millones de euros, aceptaron el plan de canje, lo que permitía al gobierno de Atenas activar el mecanismo por el que podía forzar al resto de tenedores de bonos, propietarios de otros 25.000 millones, a aceptar la operación. A estas sumas habría que añadir otros 20.000 millones en bonos de deuda pública regulados por leyes internacionales o emitidos por compañías públicas griegas, cuyos propietarios también habían aceptado la propuesta de Atenas.

Con este canje, que pasará a la historia como la mayor reestructuración de Deuda soberana, los acreedores cambiarán sus bonos por unos nuevos con un valor inferior, un interés más bajo y mayor plazo de vencimiento. Según apuntaban los expertos, estas condiciones significan que la quita del $53 \%$ se traduce en pérdidas reales del 74\% del valor de la inversión.

En Bruselas, el comisario de Asuntos Económicos y Monetarios, Olli Rehn, afirmó estar muy satisfecho con la respuesta de los inversores privados, y señaló que «constituye una contribución decisiva a la estabilidad financiera en el conjunto de la zona euro». En la misma línea, la directora gerente el FMI, Christine Lagarde, aseguró que la cooperación del sector privado es un «paso clave para situar la Economía griega en el camino del crecimiento y la estabilidad financiera».

En abril, el país daba por concluido el proceso tras lograr una participación en el canje del 96,9\% de los acreedores privados, con 199.000 millones de euros en bonos griegos (la oferta de reestructuración afectaba a 205.500 millones, de los más de 360.000 millones de euros a los que asciende la Deuda griega).

Los inversores renunciaban voluntariamente al 53\% del valor nominal de los bonos en su poder, algo más del $70 \%$ del valor neto. El canje se hizo por bonos helenos depreciados al 31,5\% de su valor, más títulos europeos al $15 \%$ de su valor, bajo legislación británica.

Según las estimaciones proporcionadas por los negociadores, Grecia conseguirá reducir en 106.000 millones de euros su Deuda - estimada en 360.000 millones - . El objetivo de la operación es situar el nivel de la Deuda pública griega en el $120 \%$ del PIB en 2020, cuando ahora supera el $160 \%$, pero no faltan analistas que dudan de que el objetivo se logre puesto que la Economía griega afronta su quinto año de recesión y la tasa de paro se situaba en diciembre de 2011 en el $21 \%$, más de seis puntos por encima del dato del mismo mes de 2010. 


\section{BCE: Nueva inyección ilimitada de liquidez a la banca europea}

El Banco Central Europeo, BCE, repitió el 29 de febrero, la operación del 21 de diciembre de 2011, poniendo a disposición de la banca europea una nueva oferta de créditos baratos e «ilimitados». La acogida por parte del sector fue incluso superior a la de Diciembre, ya que se adjudicaron 529.530 millones de euros a un tipo de interés del $1 \%$ a tres años a unas 800 entidades, cuando en la anterior «inyección de liquidez ilimitada», las peticiones habían sumado 489.000 millones procedentes de 523 entidades bancarias.

Los analistas interpretaron esta diferencia como una señal de que más bancos y cajas de ahorro de pequeño y mediano tamaño participaron en la operación. En el caso de España, los préstamos solicitados alcanzaron los 123.000 millones, una cuarta parte del total.

El presidente del BCE, Mario Draghi, reclamó que el dinero se empleara en la reactivación del crédito y en el estímulo del crecimiento, pero es muy posible que, al igual que sucedió en Diciembre, su destino sea la compra de Deuda soberana y el saneamiento de los balances bancarios. Se repetiría, de esta forma, la reacción de la banca que, aprovechando una financiación barata al 1\%, invertirán este dinero en bonos de Deuda pública, en especial de países sometidos a una fuerte presión por parte de los mercados como Italia y España, para obtener mayores rentabilidades. Sin embargo, esta rentabilidad, que buscan fundamentalmente los bancos españoles e italianos, tiene el gran inconveniente de la mayor exposición de las entidades a la crisis de la Deuda.

La medida también fue interpretada como una maniobra del BCE para sortear la intransigencia alemana en lo relativo a las compras de bonos en el mercado secundario. Con esta inyección ilimitada de liquidez a la banca, los Estados más expuestos a los mercados consiguen financiación indirecta del Banco emisor, lo que les ayuda la relajar sus «primas de riesgo». Sin embargo, también es cierto que, en estas operaciones, el BCE exige a la banca que presente determinados activos como aval, hasta que se devuelva el préstamo. De ahí surgen ciertas críticas de un sector de analistas, que creen que el BCE pudiera estar asumiendo demasiados riesgos y que la banca pudiera estar aprovisionándose en exceso con unos activos «estigmatizados», como son los bonos de los países más expuestos.

\section{Mercados Financieros: Propuesta sobre una tasa a las Transacciones Financieras}

El Parlamento Europeo expresó el 23 de mayo su respaldo a la puesta en marcha de una tasa sobre las transacciones financieras., conocida como 
«Tasa Tobin». La votación, que finalizó con un amplio consenso (487 votos a favor, 152 en contra y 46 abstenciones) no es vinculante, aunque la Eurocámara esperaba con ella enviar un claro mensaje a los Estados miembros que se oponen a la medida y, en general, a los Veintisiete ministros europeos de Finanzas se reunirán el próximo 22 de junio en Luxemburgo para debatir el asunto.

La Comisión Europea presentó el proyecto de Directiva en septiembre de 2011, con el fin de aplicar un impuesto sobre las transacciones financieras en todo el territorio de la Unión, con un gravamen del $0,1 \%$ aplicable a las operaciones sobre acciones y obligaciones y del $0,01 \%$ para otras operaciones, como las realizadas con derivados financieros.

En marzo, el presidente de la Comisión Europea, José Manuel Durao Barroso, había presentado un informe en el que se afirmaba que la introducción de la tasa a las transacciones financieras podría reducir en un 50\% las contribuciones de los Estados miembros al presupuesto de la Unión, ya que, según la propuesta, dos tercios de los ingresos se destinarían al presupuesto comunitario y uno a los nacionales. Barroso defendió la «justicia» del impuesto bancario en una rueda de prensa sobre las próximas cuentas plurianuales de la Unión para 2014-2020. «Esta cuestión es extremadamente importante. Significa más dinero del sector financiero en lugar de aportaciones de los presupuestos públicos nacionales», destacó.

Insistió en la defensa del impuesto señalando que «los bancos se han beneficiado con un gran apoyo de los contribuyentes durante la crisis y, además, no pagan suficientes tasas».

Nueve países, entre los cuales figuran Alemania y Francia, respaldan la iniciativa, mientras que Reino Unido se opone al considerar que se penalizaría la deslocalización de las actividades financieras. La esperanza de la Comisión se basa en que las reticencias mostradas por algunos Estados eran anteriores al desarrollo técnico del proyecto. «La tasa no modificará decisiones de inversión», aseguran estas fuentes, que ponen como ejemplo los 10 euros que estiman pagaría un particular por una transacción de 10.000 euros si el banco se decidiese a trasladar todo el coste al cliente.

Europa pretende recaudar unos 57.000 millones de euros al año con esta medida, una cantidad nada despreciable (equivale, por ejemplo, a todo el déficit público que proyecta registrar España en 2012), que pasaría a engrosar mayoritariamente el Presupuesto comunitario y, también, las arcas de los Estados miembros en función de su participación en la recaudación.

Como respaldo a la idea de gravar las operaciones financieras, Bruselas argumenta que dos tercios de los ciudadanos la defienden. Tal y como está diseñado, la banca soportaría el $85 \%$ del gravamen.

Pese a las dificultades, Bruselas mantiene su idea de que el gravamen pueda aplicarse el 1 de enero de 2014. 


\section{Google: denuncia de la comisión Por Abuso de Posición Dominante} en el mercado y Recurso Prejudicial ante el Tribunal de Justicia

La Comisión Europea anunció el pasado 21 de mayo un dictamen sobre las denuncias de abuso de poder de Google en el mercado comunitario.

Tras 18 meses de investigación, Bruselas constataba hasta cuatro vulneraciones del Derecho europeo de la competencia y que exigen la inmediata corrección por parte de la multinacional californiana, que controla el $86 \%$ del mercado europeo de motores de búsquedas en Internet:

- La Comisión considera que, en las búsquedas sobre su plataforma, Google trata de manera «preferencial» sus servicios, en detrimento de los de sus rivales. Como ejemplo, cita la aplicación Google Maps frente a otras similares.

- También constata que la empresa utiliza sin permiso las opiniones volcadas en otros portales. Se trata, sobre todo, de reseñas vinculadas a viajes, hoteles y restaurantes, lo que significa, según la Comisión, que Google se apropia de las inversiones realizadas por otras compañías.

- Asimismo, cuestiona los pactos comerciales que vinculan a Google con otras firmas. Con estos acuerdos, en páginas donde se despliega publicidad relacionada con las búsquedas se impide la entrada de posibles competidores (la exclusividad se considera excesiva en las búsquedas asociadas con publicidad, especialmente en las tiendas y revistas on-line).

- Por último, estima que la plataforma publicitaria de Google, AdWords, impone restricciones y dificulta que una campaña pueda trasladarse a una web alternativa (se consideran excesivas las restricciones a la portabilidad de las campañas publicitarias, relacionadas con las búsquedas en línea, a otras plataformas de competidores).

Tras la exposición de estas cuestiones, los responsables de la Comisión señalaron que esperaban una propuesta de actuaciones correctivas por parte de Google, que pudiera evitar una multa millonaria, ya que ésta podría alcanzar el 10\% de la facturación de la compañía (el año pasado la cifra de negocios del gigante norteamericano alcanzó 380.000 millones de dólares).

Joaquín Almunia, comisario de la competencia, se mostró partidario de una negociación rápida con la compañía de cara a resolver el caso lo antes posible y evitar la apertura formal de un proceso sancionador.

También recordó que existen otras investigaciones relacionadas con Google y que seguirán su camino; destaca, entre ellas, la denuncia que afecta a Android, el sistema operativo ideado por la empresa para los teléfonos móviles. 
Por otra parte, en Marzo, la Audiencia Nacional española presentó una cuestión prejudicial ante el Tribunal de Justicia de la UE que contiene una batería de preguntas en relación a la protección de datos de los particulares frente a Google, en particular respecto al «derecho al olvido» que reconoce la capacidad de una persona para suprimir y bloquear informaciones que afecten a su privacidad o a su dignidad.

Hasta ahora, reclamaciones similares planteadas en Francia o en Italia, han sido derivadas por los jueces de estos países a los tribunales de EE UU, donde Google tiene su sede. Este es precisamente el eje de la argumentación del buscador, ya que alega que al estar ubicado en California se encuentra fuera del ámbito de aplicación de la normativa española y que solo está sometido a la jurisdicción de EE UU sobre protección de datos. Sin embargo, la Audiencia Nacional afirma que la tutela de un derecho fundamental no puede depender del lugar que el gestor del buscador haya elegido «para ubicar los medios técnicos».

La Audiencia quiere saber si las leyes que rigen en la UE se pueden aplicar en este caso contra Google; si los buscadores, cuando indexan la información, están realizando un tratamiento de datos personales, y si la protección de datos incluye el «derecho al olvido», es decir, si una persona se puede negar a que informaciones que le afectan (aunque sean lícitas y exactas) sean retiradas porque considere que son negativas o perjudiciales para su dignidad.

\section{Tarifas máximas en la conexión a internet a través del teléfono móvil}

Hace ya años que la Comisión estableció tarifas máximas sobre los precios de las llamadas y los mensajes de texto, sms, realizados con los teléfonos móviles cuando los ciudadanos viajan a otro país de la Unión Europea.

Pero quedaba pendiente la intervención respecto a las tarifas en la navegación por Internet móvil. La generalización de los «smartphones» (teléfonos inteligentes) y de las «tabletas» hacía urgente esa regulación, ya que actualmente los operadores pueden cobrar tarifas muy elevadas a sus clientes en el extranjero cuando éstos acceden a internet o consultan su correo electrónico desde sus móviles (las tarifas pueden alcanzar 4 euros por mega descargado).

El Parlamento Europeo aprobó la propuesta de la Comisión en mayo, con el fin de recortar drásticamente estas tarifas, de tal manera que, a partir del próximo 1 de julio, las operadoras podrán cargar como máximo 70 céntimos por cada megabyte descargado (más IVA), precio máximo que se reducirá a 45 céntimos en julio de 2013 y a 20 céntimos en julio de 2014. Según los cálculos de la Comisión, el Reglamento permitirá ahorrar al menos 
200 euros a una familia que pase sus vacaciones en el extranjero y más de 1.000 euros al año a los empresarios que viajen por la UE.

En esta batalla por abaratar Internet en movilidad ha jugado un papel protagonista la comisaria de Telecomunicaciones, Neelie Kroes, verdadero azote de las operadoras cuyos márgenes de beneficio en las comunicaciones desde el extranjero considera abusivas. «Hemos acabado con las estafas que conocen todos los que han utilizado un teléfono móvil mientras están de viaje», señaló.

La rebaja también afecta a llamadas y los sms que se realicen o se reciban desde otro país de la UE, aunque estos ya tenían limitado su precio máximo con anterioridad. A partir del 1 de julio, se reducirá de 35 a 29 céntimos el máximo de la llamada por minuto; a 24 céntimos desde julio de 2013 y a 19 céntimos un año después. Los mensajes de texto también serán más baratos, puesto que bajarán de los actuales 11 céntimos hasta los 9 céntimos el próximo 1 de julio y, posteriormente, a 6 céntimos en julio de 2014.

\section{Reforma del Tratado Schengen}

El Consejo de ministros de Interior de la Unión Europea decidió el 7 de junio reformar el Tratado Schengen para que los Estados puedan reintroducir controles fronterizos temporales en caso de que un Estado se vea desbordado e incapaz de controlar los flujos migratorios en sus puestos aduaneros.

Esta reforma de Schengen tiene su origen en los éxodos provocados por la «primavera árabe» del Magreb, que evidenciaron ciertos puntos débiles en el sistema. Los Veintiséis miembros del Acuerdo (Veintidós de la UE y Cuatro no comunitarios) estaban de acuerdo en la necesidad de modificarlo y la Comisión propuso en Septiembre de 2011 ser el garante de las nuevas excepciones del Tratado, obligando a los Estados a solicitarle la autorización para poder reintroducir los controles.

Sin embargo, según el acuerdo alcanzado serán los Gobiernos quienes gestionen el nuevo régimen, dejando fuera del proceso a la Comisión y al Parlamento Europeo, y explicitando de esta manera su rechazo a la fiscalización de las instituciones europeas.

En el Parlamento se escucharon opiniones de rechazo. «Con esta decisión, los ministros han enviado una señal clara: que encontrarán cualquier pretexto para cerrar las fronteras», se indignó el jefe de los liberales y ex primer ministro belga Guy Verhofstadt. El propio presidente de la Eurocámara, Martin Schulz, señaló que «la libre circulación en el espacio interior es un pilar de la UE, una de las ventajas más palpables, y el Parlamento luchará para reforzarla». 
Los Estados acordaron, en efecto, permitir la reintroducción de controles de pasaporte en caso de avalancha migratoria en una de las fronteras exteriores de la UE. Si uno de los socios que controla el perímetro exterior de la Unión se viera desbordado por la llegada de inmigrantes, el resto podría colocar temporalmente puestos de control en carreteras y aeropuertos. En principio, la medida podría prolongarse durante seis meses, pero este plazo podría eventualmente llegar a dos años tras sucesivas prórrogas.

Hasta ahora los gobiernos sólo podían restaurar las fronteras por una amenaza a la seguridad o durante la celebración de grandes eventos, tal como hizo España con motivo de la reunión del Consejo de Gobierno del Banco Central Europeo celebrada en Barcelona en mayo, restableciendo temporalmente los controles fronterizos con Francia.

Ante las críticas de la Comisión y del Europarlamento, los Estados insistieron en que sólo se impondrán fronteras temporales en «circunstancias excepcionales», y como último recurso. En todo caso, el acuerdo alcanzado entre los Gobiernos es político y todavía tiene por delante un proceso de discusión con la Comisión y el Parlamento. 